\title{
Public debt and aggregate risk
}

\author{
Audrey Desbonnet* \\ CES - Université de Paris I
}

Sumudu Kankanamge ${ }^{\dagger}$

CES - Université de Paris I

Novembre 2006 - Preliminary Version

\begin{abstract}
This paper assesses the optimal level of public debt in a new framework where aggregate fluctuations are taken into account. We find that the optimal level of public debt is higher when fluctuations at the macro level are considered when compared to an economy that leaves them aside. To show that we quantitatively assess the channels through which public debt impacts the economy. We find that incomplete markets, credit constraints and price fluctuations play an important role. In particular, interest rate increases due to higher debt benefits rich agents and deprives poor agents.
\end{abstract}

Key words : debt, aggregate risk, liquidity constraints, incomplete markets JEL classification: E32, E63, H31

*Address: CES, Université de Paris I, MSE 106-112 Bd de l'Hôpital, 75447 Paris Cedex $13 . \quad$ Email:audrey.desbonnet@univ-paris1.fr

${ }^{\dagger}$ Address: CES, Université de Paris I, MSE 106-112 Bd de l'Hôpital, 75447 Paris Cedex $13 . \quad$ Email:kankanamge@univ-paris1.fr 


\section{Introduction}

The level and the effects of public debt are important issues to be examined from a quantitative point of view. Over the postwar period the U.S. average debt over GDP ratio has been stagnating around the figure of two-third ${ }^{1}$. Previous work argue that a positive level of debt such as this one has either benefits or drawbacks or both of them using very different settings ${ }^{2}$. Since Woodford (1990) a framework embedding incomplete markets and credit constraints has been used to assess public debt policies. Market incompleteness and credit constraints are important features to consider when evaluating public debt for at least two reasons. First such a framework is adequate to assess the redistributive impact of public debt. Second market incompleteness influences capital accumulation and introduces precautionary saving that taxation to support public debt can distort. Thus the level of market completeness, credit constraints or price behavior are known elements to consider when explaining the role of public debt. Still there is no clear quantification in the literature of the impact of the former elements and the most realistic settings used sofar consider only idiosyncratic risk.

This paper's main objective is to implement a new framework exhibiting aggregate risk to quantify the optimal level of public debt. Recent work such as Krusell and Smith (2002) or Storesletten, Telmer and Yaron (2001) suggest that aggregate fluctuations have an important impact on the economy and generate costs. As argued by Algan and Allais (2004) aggregate fluctuations may lead to both an employment fluctuations effect where savings and borrowing are less likely to smooth consumption during longer unemployment spells and to a price fluctuation effect where fluctuations of wages and interest rates could generate important redistributive effects depending on households' asset holding. Public debt provides households with an additional asset to smooth their consumption. Aggregate risk by augmenting the overall risk level changes household's consumption and saving decisions what in turn impact their demand for asset. Households have now to respond to price fluctuations thus aggregate risk might change the optimal level of debt in the economy. To support our main objective we decompose our general model into simpler ones and look more closely at the importance of market incompleteness, credit constraints, distortive taxa-

\footnotetext{
${ }^{1}$ Aiyagari and McGrattan (1998) state that this figure is an average of the U.S. federal plus U.S. state debt divided by gross domestic product.

${ }^{2}$ See for instance Auerbach and Kotlikoff (1987), Barro (1989), Woodford (1990), Aiyagari and McGrattan (1998) or Floden (2001).
} 
tion and price behavior on the redistributive impact of debt and thus clarify the channels through which public debt impacts the economy.

Following Bewley-Huggett-Aiyagari type models, we build a production economy with capital market imperfections where a large number of ex-ante identical infinitely-lived agents face idiosyncratic income shocks, aggregate productivity shocks - that exacerbate the former shocks - and preference shocks. Household level saving behavior is influenced by precautionary saving motives and borrowing constraints. Private capital and government bonds, both yielding the same interest, can be claimed to insure against future risk. Government levies proportional taxes on the households and issues debt in order to finance its consumption. In this framework we can reassess the optimum quantity of debt and capture the benefits and the costs of different values of the debt over GDP ratio.

The main contribution of this paper is to quantitatively evaluate the optimum quantity of debt when the economy is subject to aggregate risk. To do that we cross an Aiyagari and McGrattan (1998) type model used to evaluate the optimum level of public debt when the risk is only idiosyncratic with a Krusell and Smith (1998) type model used to assess the impact of aggregate productivity shocks on the economy. In this setting we quantitatively measure the impact of different levels of public debt on the output, the capital stock, the interest rates and the welfare. We find that the optimum level of debt is $65 \%$ of GDP. Next we also evaluate this optimum quantity of debt when there is no aggregate level fluctuations. To do that we follow Imrohoroglu (1989) and average the employment process over bad and good periods and keep the same calibration as in the general model otherwise. This comparison model without aggregate fluctuations yields an optimum level of debt of $60 \%$. Thus we show that there is a quantitatively tangible effect of aggregate fluctuations on the optimal level of debt.

The intuition for that result is the following. Credit constraints and uncertainty lead agents to engage in precautionary saving. The result of precautionary savings is a higher level of capital what in turn mechanically lowers the interest rate away from the time preference rate. Aggregate fluctuations exacerbate overall risk level in the economy leading agents to engage in even more precautionary saving. The capital stock rises and the interest rates goes further away from the time preference rate. Higher levels of public debt crowd out private capital and raise the interest rate, getting it closer to the time preference rate. Simultaneously, higher interest rates lower the 
cost of precautionary saving. Thus households are better off with a positive level of debt when the economy is subject to aggregate fluctuations. The movements of the interest rate are crucial here to understand why agents prefer higher levels of public debt. When we test for the same mechanism in a price fixed small open economy, the optimal level of debt is much lower than the levels mentioned above and is no more positive.

We also find that not being at the optimal level of debt is not very costly in terms of welfare. This result is the same as in Aiyagari and McGrattan (1998). But this is no more the case when we consider smaller fractions of the population. We find, as discussed by Ball and Mankiw (1995) and Floden (2001), that rich agents prefer higher levels of debt whereas poor agents prefer lower level of debt. Higher taxes and crowding out of capital harm all agents but only rich people, whose main income is the return on the assets they hold, benefit from high levels of interest rates.

To clarify our main mechanism we decompose our general model into more intuitive ones. We start from the simplest possible complete market model where debt has no impact on capital, output or welfare and add successive features such as incomplete markets, credit constraints, distortive taxes and small open economy features. We find that public debt is welfare enhancing if the eventuality of being credit constrained is high enough to induce households into precautionary saving. The price fixed small open economy shows that the welfare enhancement concerns mainly rich people because higher interest rates lowers the cost of precautionary saving. Eventually we find that distortive taxes does not strongly change the impact of public debt on the economy.

\section{Related literature}

To the best of our knowledge, our paper is the first one to look at the optimal quantity of debt when the economy is subject to aggregate fluctuations. Nevertheless previous literature study questions similar to ours in settings closely related. The first author to depart from the complete markets framework for the analysis of debt is Woodford (1990) although the setting he uses was introduced by Bewley (1980) to study the optimal quantity of money. Woodford (1990) models a simple economy embedding credit constraints and shows that public debt is efficient because it keeps interest rates higher and closer to the time preference rate. But this paper does not provide any quantitative result concerning public debt. Aiyagari and McGrattan (1998) are the first authors to address the question of the optimal level of public debt and give answers in quantitative terms. The authors argue that on the positive side public debt relaxes the liquidity constraint of households 
and thus is welfare enhancing but that on the negative side it crowds out private capital and distorts saving decisions through higher taxes. Calibrating on the U.S. economy they find that a debt over GDP ratio of $2 / 3$ is optimal, this level being precisely the observed ratio in the U.S. over the postwar period. Eventually Aiyagari and McGrattan (1998) underline that it is not very costly to switch to other levels of debt, the computed welfare profile being flat. However this model embeds no aggregate fluctuations properties but is very close to our comparison model without aggregate fluctuations. Floden (2001) uses the framework in Aiyagari and McGrattan (1998) to look at public debt/transfers optimal combinations. The author argues that public debt is welfare enhancing but that a positive level of debt is optimal only if transfers are fixed at a suboptimal level. Moreover this paper shows that an overall flat welfare profile can hide important gains or losses due to changes in uncertainty or inequality. Again this model does not consider aggregate fluctuations. Finally this paper is also related to that of Heathcote (2005). The author assesses the deviations to Ricardian equivalence using several settings of taxation, capital market imperfection and intergenerational altruism. The main finding is that a combination of distortive taxes and capital market imperfections generates important departures from Ricardian equivalence. The most complete setting considered in Heathcote (2005) models bounded debt over GDP ratios and embeds aggregate risk deriving from a stochastic tax rate. However in our setting the aggregate risk considered comes directly from aggregate productivity shocks that impact both prices and tax levels but also the idiosyncratic risk level of our economy.

This paper is organized as follows. Next section describes the benchmark economy. Section 3 details the results. The last section concludes.

\section{The Benchmark Model}

Our benchmark economy is a Bewley-Huggett-Aiyagari type dynamic stochastic general equilibrium model augmented to allow aggregate fluctuations à la Krusell and Smith (1998) and public debt.

\subsection{Firms}

Our setting assumes that all markets are competitive. Each period one good is produced by a representative firm using a Cobb-Douglas technology. The output is given by 


$$
Y_{t}=z_{t} F\left(K_{t}, N_{t}\right)=z_{t} K_{t}^{\alpha} N_{t}^{1-\alpha} \quad 0<\alpha<1
$$

where $K$ is aggregate capital and $N$ aggregate labor used in production. Capital depreciates at a constant rate $\delta$. The economy is subject to an exogenous aggregate shock noted $z$. There are two possible aggregate states: a good state where $z=z_{g}$ and a bad state where $z=z_{b}$. The aggregate shock follows a first-order Markov process with transition probability $\pi_{z \mid z^{\prime}}$. Thus $\pi_{z \mid z^{\prime}}$ is the probability that the aggregate state tomorrow is $z^{\prime}$ given that it is $z$ today.

\subsection{The government}

The government issues public debt and levies taxes to finance public expenses. Both the revenue of capital and labor are taxed proportionally at an identical rate $\tau$. The government's budget constraint verifies

$$
G_{t}+r_{t} B_{t}+\Pi_{t}=B_{t+1}-B_{t}+T_{t}
$$

$G_{t}$ is the level of public expenses, $B_{t}$ the level of public debt, $T_{t}$ tax revenues and $\Pi_{t}$ a lump sum transfer to households that amounts to zero in equilibrium. We assume that public expenses are constant in every period.

\subsection{Households}

The economy is populated by a continuum of ex ante identical infinitely lived households of unit mass that maximize expected utility of consumption $c$. Agents are subject to idiosyncratic shocks on their labor market status $s$ and thus can be in an unemployed state when $s=0$ and in an employed state when $s=1$. Aggregate productivity shocks and idiosyncratic labor market shocks are correlated thus the only source of aggregate risk is the aggregate productivity shock $z$. We note $\pi_{s z \mid s^{\prime} z^{\prime}}$ the joint transition probability to a state $\left(s^{\prime}, z^{\prime}\right)$ conditional on a state $(s, z)$. The number of unemployed agents are always equal to $u_{g}$ in the good state and to $u_{b}$ in the bad state. We also assume that agents' discount factors $\beta$ are random. Thus $\beta^{\prime}=\tilde{\beta} \beta$ and $\tilde{\beta}$ follow a two-states first-order Markov process with transition probability $\pi_{\tilde{\beta} \mid \tilde{\beta}^{\prime}}$.

We rule out insurance markets for idiosyncratic risk by assumption so that the only available 
markets are the private capital market and the government bond market. Following Aiyagari and McGrattan (1998) no borrowing is allowed but households can self-insure against idiosyncratic risk by accumulating private capital and government bonds both yielding the return $r$. Their overall holding in the later assets is noted $a$.

Therefore a typical household solves the following problem:

$$
\begin{gathered}
\max _{c_{t}, a_{t+1}} \mathbb{E}_{0}\left\{\sum_{t=0}^{\infty}\left(\prod_{j=0}^{t} \beta_{j}\right) u\left(c_{t}\right)\right\}, \\
\text { s.t. } a_{t+1}+c_{t}=\left(1+(1-\tau) r_{t}\right) a_{t}+\chi\left(s_{t}\right) w_{t}+\Pi_{t} \text { with } c_{t}, a_{t+1} \geq 0
\end{gathered}
$$

and

$$
\chi\left(s_{t}\right)=\left\{\begin{array}{l}
\theta \text { if } s_{t}=0, \\
(1-\tau) \text { if } s_{t}=1
\end{array}\right.
$$

where $\theta$ is the home production effort ratio of an unemployed agent.

In each period, the individual and aggregate state variables are summarized by the vector $(a, s, \beta ; z, \Gamma)$ where $\Gamma(a, s, \beta)$ is the distribution of agents over asset holdings, employment status and preference. We detail the computational strategy we used to solve the model in appendix A.

\subsection{Equilibrium}

The recursive equilibrium consists of a set of decision rules for consumption and asset holding $\left\{c(a, \beta ; z, \Gamma), a^{\prime}(a, s, \beta ; z, \Gamma)\right\}$, aggregate capital $K(z, \Gamma)$, factor prices $\{r(z, \Gamma), w(z, \Gamma)\}$, tax rate $\tau$ and a law of motion for the distribution $\Gamma^{\prime}=H\left(\Gamma, z, z^{\prime}\right)$ which satisfy these conditions:

(i) Given the aggregate states, $\{z, \Gamma\}$, prices $\{r(z, \Gamma), w(z, \Gamma)\}$ and the law of motion for the distribution $\Gamma^{\prime}=H\left(\Gamma, z, z^{\prime}\right)$, the decision rules $\left\{c(a, s, \beta ; z, \Gamma), a^{\prime}(a, \epsilon, \beta ; z, \Gamma)\right\}$ solve the following dynamic programming problem:

$$
v(a, s, \beta ; \Gamma, z)=\max _{c, a^{\prime}}\left\{U(c)+\beta E\left[v\left(a^{\prime}, s^{\prime}, \beta^{\prime} ; z^{\prime}, \Gamma^{\prime}\right) /(s, \beta ; z, \Gamma)\right]\right\}
$$


subject to:

$$
\begin{aligned}
& c+a^{\prime}=(1+r(z, \Gamma)(1-\tau)) a+w(z, \Gamma) \chi(s)+\Pi \\
& c \geq 0 \\
& a^{\prime} \geq 0
\end{aligned}
$$

and

$$
\Gamma^{\prime}=H\left(\Gamma, z, z^{\prime}\right)
$$

(ii) Market price arrangements are:

$$
\begin{aligned}
& r(z, \Gamma)=\alpha z K^{\alpha-1} N^{1-\alpha}-\delta \\
& w(z, \Gamma)=(1-\alpha) z K^{\alpha} N^{-\alpha}
\end{aligned}
$$

(iii) Government budget constraint is balanced.

(iv) Capital Market clears when:

$$
K=\int a^{\prime}(a, \epsilon, \beta ; \Gamma, z, B) d \Gamma-B
$$

(v) Consistency: agents' optimization problem is satisfied given the law of motion $H$ and the law of motion is consistent with individual behavior.

\subsection{Calibration}

The model period is one quarter and it is calibrated on the U.S. economy. We target the key capital-output ratio.

\section{Technology and preferences}

Table 1 reports the benchmark calibration for preference and technology. Technology parameters are standard: capital share of output is set to 0.36 and capital depreciation rate is 0.025 .

The utility function we use has a standard CRRA specification and writes

$$
u(c)=\frac{c^{1-\sigma}}{1-\sigma} .
$$


For the benchmark economy we assume a risk aversion parameter of 1.0 thus our utility function becomes $\log (c)$. Following Carroll (2000) we assume that the discount factor $\beta$ can take on two values. We set those values to 0.9876 and 0.9982 . The transition probabilities are such that (a) the invariant distribution for $\beta$ 's has $60 \%$ of the population at the low (impatient) $\beta$ and $40 \%$ at the high (patient) $\beta$, (b) the average duration of the lowest $\beta$ is 50 years. The transition matrix for discount factors is:

$$
D=\left(\begin{array}{ll}
0.9950 & 0.0050 \\
0.0075 & 0.9925
\end{array}\right)
$$

Aggregate shock and labor market processes

Our calibration of the aggregate shock and the labor market process closely follows Krusell and Smith (1998). The aggregate shock values are $\left\{z_{g}=1.01 ; z_{b}=0.99\right\}$. The process for $(z, s)$ is set so that the average duration of good and bad times is eight quarters. The average duration of an unemployment spell is 1.5 quarters in good times and 2.5 quarters in bad times. We also set the unemployment rate accordingly: in good periods it is $4 \%$ and in bad periods it is $10 \%$. We also define transition matrixes for labor market status for each aggregate state switch: $\Upsilon^{g g}$ for a transition from a good period to a good period, $\Upsilon^{b b}$ for a transition from a bad period to a bad period, $\Upsilon^{g b}$ for a transition from a good period to a bad period and $\Upsilon^{b g}$ for a transition from a bad period to a good period $^{3}$ :

$$
\begin{gathered}
\Upsilon^{b b}=\left(\begin{array}{cc}
0.6 & 0.4 \\
0.0445 & 0.9555
\end{array}\right) \quad \Upsilon^{b g}=\left(\begin{array}{cc}
0.25 & 0.75 \\
0.0167 & 0.9833
\end{array}\right) \\
\Upsilon^{g b}=\left(\begin{array}{cc}
0.75 & 0.25 \\
0.0729 & 0.9271
\end{array}\right) \Upsilon^{g g}=\left(\begin{array}{ll}
0.3333 & 0.6667 \\
0.0278 & 0.9722
\end{array}\right)
\end{gathered}
$$

We then calibrate a transition matrix $\eta$ for aggregate state switches:

$$
\eta=\left(\begin{array}{ll}
0.875 & 0.125 \\
0.125 & 0.875
\end{array}\right)
$$

Finally the joint transition matrix $\Upsilon$ for labor market statuses and aggregate state can be defined as:

\footnotetext{
${ }^{3}$ Further detail on this calibration can be found in Krusell and Smith (1998) and Krusell and Smith (2002)
} 


$$
\Upsilon=\left(\begin{array}{cc}
\eta_{b b} \Upsilon^{b b} & \eta_{b g} \Upsilon^{b g} \\
\eta_{g b} \Upsilon^{g b} & \eta_{g g} \Upsilon^{g g}
\end{array}\right)
$$

The home production effort ratio $\theta$ is set to 0.1 as in Krusell and Smith (1999).

\section{Government}

We assume that the ratio of public debt to GDP $g$ is 0.217 as in Aiyagari and McGrattan (1998). In our benchmark economy, the debt over GDP ratio is initially set to $2 / 3$.

This calibration yields a quarterly capital/output ratio of 11.0 and a Gini coefficient of 0.57. For the benchmark debt over GDP ratio the tax rate $\tau$ is 0.30 .

Table 1: Benchmark calibration

\begin{tabular}{ccccccc} 
Parameters & $\beta_{1}$ & $\beta_{2}$ & $\sigma$ & $\alpha$ & $\delta$ & $\theta$ \\
\hline Values & 0.9876 & 0.9982 & 1.0 & 0.36 & 0.025 & 0.1 \\
\hline \hline
\end{tabular}

\section{Results}

This section first examines the long-run welfare effects of debt in an aggregate fluctuations setting. These findings are then compared to a setting where there is no aggregate fluctuations. We then explore simpler settings to understand the channels through which public debt impacts the economy.

\subsection{Optimal level of debt in an aggregate fluctuation setting}

We start by discussing the aggregate behavior of our benchmark model. As shown in table 2 and figure 1, our benchmark economy exhibits well-known properties as the level of public debt increases. Public debt has a crowding-out effect on private capital: higher levels of debt decrease the aggregate amount of private capital in the economy and consequently lower the output and increase the interest rate. However the overall wealth level $A$, that is the combination of private capital and public debt, is increasing. As expected the tax rate also increases with higher levels of debt.

Figure 2 depicts the optimal level of debt we find in our benchmark economy. In a setting embedding aggregate risk and calibrated on the U.S. economy, the optimal public debt level is $65 \%$ of output. Households are better off with a positive amount of public debt because of the combined 
Table 2: Evolution of key macro variable in the benchmark economy

\begin{tabular}{cccccccc}
$B / Y$ & 0.00 & 0.20 & 0.40 & 0.60 & $2 / 3$ & 0.80 & 1.00 \\
\hline$K$ & 100.77 & 100.54 & 100.31 & 100.07 & 100.00 & 99.87 & 99.66 \\
$A$ & 94.87 & 96.41 & 97.95 & 99.48 & 100.00 & 101.04 & 102.59 \\
$Y$ & 100.28 & 100.19 & 100.11 & 100.03 & 100.00 & 99.95 & 99.88 \\
$r$ & 98.10 & 98.66 & 99.24 & 99.82 & 100.00 & 100.34 & 100.85 \\
$w$ & 100.28 & 100.19 & 100.11 & 100.03 & 100.00 & 99.95 & 99.88 \\
$\tau$ & 98.35 & 98.84 & 99.34 & 99.83 & 100.00 & 100.34 & 100.85 \\
\hline \hline
\end{tabular}
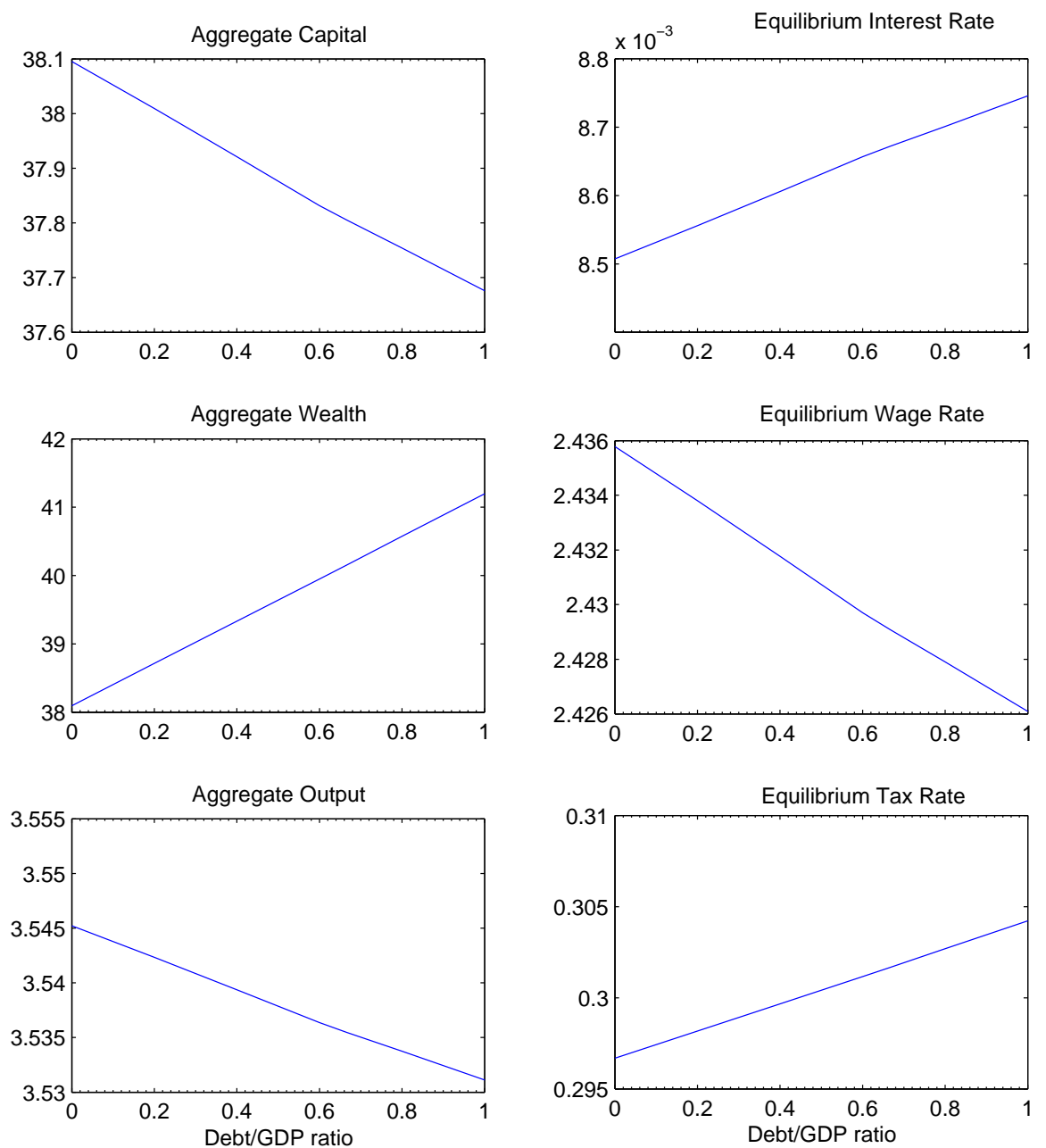

Figure 1: Equilibrium key macro variables in the benchmark economy

effect of credit constraints and the risky environment. Credit constraints and unemployment risk lead agents into precautionary savings to smooth their consumption. This effect is even stronger when aggregate fluctuations exacerbate idiosyncratic labor market risk. Thus the amount of aggre- 
gate capital increases and the interest rate decreases. Woodford (1990) argues that in such a setting welfare can be enhanced if the interest rates are kept high enough, that is, closer to time preference rates. This is the role public debt plays here. The crowding-out of private capital increases the interest rates and thus ameliorates the efficiency in the economy.

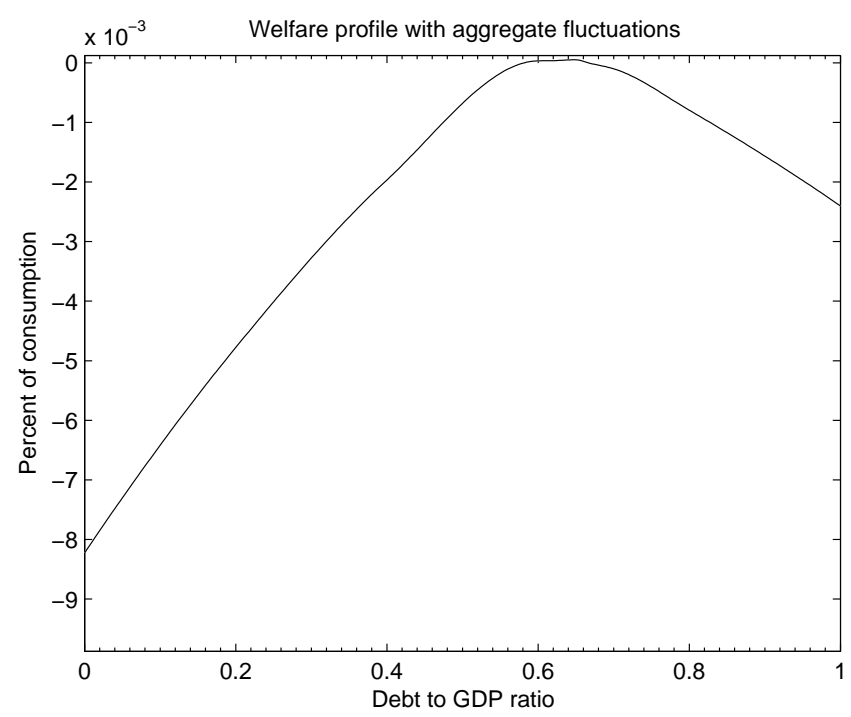

Figure 2: Welfare gain versus debt/GDP ratio in the benchmark model

As illustrated in table 3, switching from the benchmark level of debt to an economy without debt has a consumption cost of $0.0082 \%$. It is also weakly welfare decreasing to switch to a higher level of public debt: in an economy where debt amount to $100 \%$ of GDP the consumption loss would be $0.0024 \%$. But this cost is shared very differently in the population. To show that we decompose the welfare gains from public debt. For instance column Least fortunate $5 \%$ in table 3 shows the welfare difference between the $5 \%$ least fortunate people living in an economy with a benchmark level of public debt and those living in an economy without debt. This decomposition closely matches a decomposition by wealth levels and we use alternately the terms least (resp. most) fortunate or poorest (resp. richest). It would benefit the poorest agents to have lower levels of debt: switching from the benchmark debt level to an economy without debt would give a further $0.85 \%$ of consumption to the poorest $5 \%$ of the population whereas it would cost $0.79 \%$ of consumption to the richest $5 \%$ of the population. This derives from the fact that rich people's income is mainly capital income. Conversely, poor people rely mostly on labor income. Thus when the level of public debt is higher all agents suffer from the reduction in output caused by higher taxes and crowding 
out of capital while only rich people gain from the higher return on capital ${ }^{4}$. In the long run the latter effect dominates and explains the positive optimal level of public debt.

Table 3: Consumption cost of switching to an economy without debt in the benchmark model

(\%) Consumption cost of population

\begin{tabular}{ccccc} 
All & Least fortunate $5 \%$ & Least fortunate 25\% & Most fortunate $5 \%$ & Most fortunate $25 \%$ \\
\hline-0.0082 & 0.8479 & 0.6804 & -0.7954 & -0.4509 \\
\hline \hline
\end{tabular}

\subsection{Optimal level of debt without aggregate fluctuations}

To have a comparison point we next look at a setting without aggregate fluctuations. To build that setup we first average the aggregate shock to it's mean and then we follow Imrohoroglu (1989) to derive the labor market process. The transition probabilities of this economy are set so that the average rate of unemployment and the average duration of an unemployment spell are the same across this economy and the benchmark economy. All other calibration parameters are kept to their benchmark values, specially time preference rates and the risk aversion parameter.

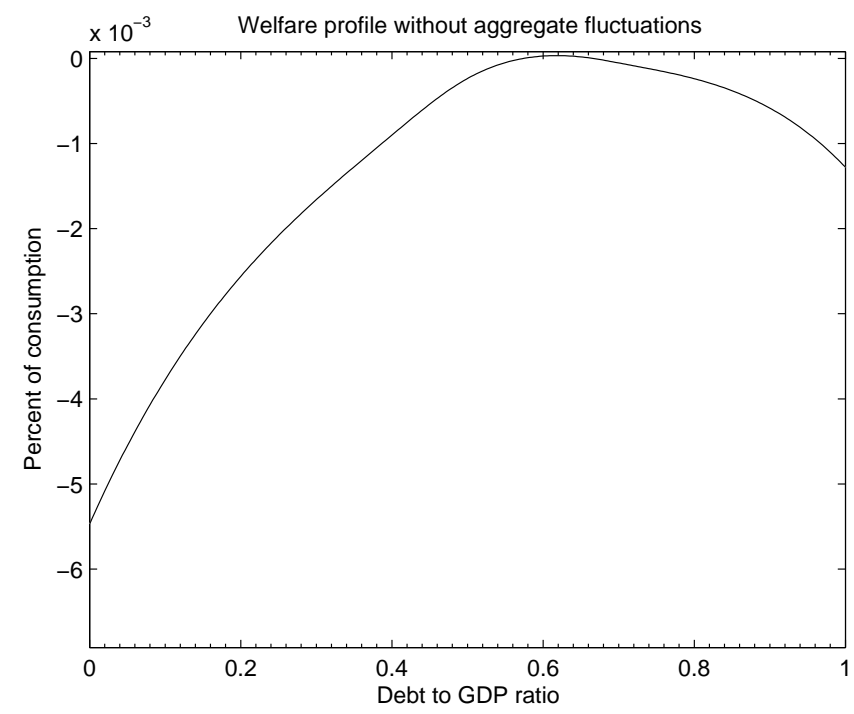

Figure 3: Welfare gain versus debt/GDP ratio in the model without aggregate fluctuations

Figure 3 depicts the welfare profile we find in this idiosyncratic risk only model. The optimal level of public debt is $60 \%$ of output. This level is lower than the level we found in the benchmark economy. That is because the risk is greater in the benchmark economy. Agents are subject to a

\footnotetext{
${ }^{4}$ This effect is discussed in Ball and Mankiw (1995) and Floden (2001).
} 
riskier labor market and at the same time they face price fluctuations. Thus their precautionary saving motive is stronger in the benchmark economy. Consequently aggregate capital increases whereas the interest rate lowers. The need for public debt is then stronger as the crowding-out property of public debt is capable of keeping the interest rates close to the time preference rate. Table 4 underline that the welfare profile is also flat in this economy but that the costs are again different when considering rich and poor people.

Table 4: Consumption cost of switching to an economy without debt in the idiosyncratic risk model

(\%) Consumption cost of population

\begin{tabular}{ccccc} 
All & Least fortunate $5 \%$ & Least fortunate 25\% & Most fortunate 5\% & Most fortunate 25\% \\
\hline-0.0055 & 0.8316 & 0.7089 & -0.8291 & -0.4675
\end{tabular}

We also use this setting without aggregate fluctuations to assess the effect of prices. To do that we consider a price fixed small open economy very close to the model in this section. We emphasized earlier that public debt through the crowding-out property kept interest rates higher and consequently enhanced welfare. Our small open economy setting shows that when prices are fixed we loose all positive effect of public debt. This result is reported in table 5 . We start with a price taker economy that has no debt. We then suppose that the government engages in a policy that consists in getting public debt to $20 \%$ of output. In the long-run such a policy is not welfare enhancing when the prices are fixed. Even the richest population are worse off in this situation.

Table 5: Cost of the introduction of public debt in a small open economy

(\%) Consumption cost of population

\begin{tabular}{cccc} 
& All & Least fortunate $5 \%$ & Most fortunate $5 \%$ \\
\hline Closed economy & 0.0029 & -0.2465 & 0.2582 \\
Small open economy & -0.3955 & -0.2640 & -0.5166 \\
\hline \hline
\end{tabular}

\subsection{Debt channels}

In this section we inspect different settings in order to disentangle the channels through which public debt impacts the economy. Our general approach will be to consider a closed economy initially without debt. The government will then engage in a policy that consists in getting public debt to $20 \%$ of output.

We start with a complete market setup where taxation and transfers have no distorting effects. 
Namely there are no transfers and we tax proportionally labor income. As labor supply is exogenous there will be no distortions. In this setup the introduction of public debt does not have any redistributive effect on any fraction of the population and is not welfare improving. There are no constrained agents. Model $C M$ in table 6 reports this result. Complete markets help household modify their asset holding and their consumption as the level of debt changes. Thus there is no intra-period heterogeneity between the agents because they can all respond accordingly to changes in the debt level. Consequently there is no intertemporal heterogeneity.

Table 6: Impact of public debt under alternative settings for market completeness and credit constraints

\begin{tabular}{ccccc} 
& \multicolumn{3}{c}{ (\%) Consumption cost of population } & (\%) Constrained \\
& All & Least fortunate $5 \%$ & Most fortunate 5\% & agents \\
\hline$C M$ & 0.0000 & 0.0000 & 0.0000 & 0.0000 \\
$I M_{1}$ & -0.3009 & -0.4586 & -0.2873 & 0.0148 \\
$I M_{2}$ & 0.0226 & -0.3295 & 0.3095 & 0.8449 \\
$I M_{3}$ & 0.0549 & -0.4059 & 0.4238 & 1.5482 \\
\hline \hline
\end{tabular}

We next explore settings with incomplete markets. We introduce incomplete markets by specifying a labor productivity shock and the impossibility to perfectly insure against that risk. The only mean for insurance is initially the private capital market. After the debt policy, agents have also access to the public bond market. Credit constraints are introduced by supposing that agents can not borrow. Thus agents must engage in precautionary saving to smooth their consumption. We still impose that only labor income is proportionally taxed. Table 6 reports the results we obtain in this setting when the number of credit constrained agents increases. The number of credit constrained agents are controlled by artificially loosening agents's time preference rate. In our $I M_{1}$ setting credit constrained agents are close to zero since only $0.0148 \%$ of total population is constrained. We find that introducing debt in this economy is not welfare enhancing for any percentile of the population. This result suggest that when the eventuality of being credit constrained is low, agents save less and thus they have little interest in public debt as a way to lower their precautionary saving cost. Thus public debt is less useful.

Setting $I M_{2}$ and $I M_{3}$ consider economies with higher numbers of credit constrained agents. In those economies we find that the introduction of public debt is welfare enhancing. A closer look at population percentiles show that not everybody benefits from higher levels of public debt. Poor people do not gain from higher debt whereas rich people do. Higher interest rates make the cost 
Table 7: Impact of public debt under price fixed small open economy

\begin{tabular}{ccccc} 
& \multicolumn{3}{c}{ (\%) Consumption cost of population } & (\%) Constrained \\
& All & Least fortunate $5 \%$ & Most fortunate $5 \%$ & agents \\
\hline$I M_{3}$ & 0.0549 & -0.4059 & 0.4238 & 1.5482 \\
$I M_{4}$ & -0.3699 & -0.3745 & -0.3194 & 1.5482 \\
\hline \hline
\end{tabular}

of precautionary saving lower for rich people whereas poor people who are more concerned with higher taxes and lower wages see little benefit in higher debt levels. Setting $I M_{4}$ reported in table 7 illustrates that argument: $I M_{4}$ is the same setting as $I M_{3}$ except that we impose fixed prices. The consumption cost is lower for poor people in this setting and the remaining cost is due to the increasing tax rate. This time higher debt is also costly for rich people. They sustain the cost of higher taxes on labor income without the benefits of higher return on their capital assets for their precautionary saving motive.

In the setting $I M_{5}$ reported in table 8 we try to enhance the liquidity of poor unemployed households. To do that we tax the domestic income of unemployed agents so that their borrowing constraint is relaxed when the level of public debt rises ${ }^{5}$. We find that in the long term, poor agents are more sensible to higher taxes than to the relaxing of their credit constraint. However rich agents are better off because taxes are now shared among the whole population.

Table 8: Impact of public debt when unemployed agents are taxed

\begin{tabular}{|c|c|c|c|c|}
\hline & \multicolumn{3}{|c|}{ (\%) Consumption cost of population } & \multirow{2}{*}{$\begin{array}{c}\text { (\%) Constrained } \\
\text { agents }\end{array}$} \\
\hline & All & Least fortunate $5 \%$ & Most fortunate $5 \%$ & \\
\hline$I M_{3}$ & 0.0549 & -0.4059 & 0.4238 & 1.5482 \\
\hline$I M_{5}$ & 0.0557 & -0.4076 & 0.4347 & 1.1170 \\
\hline
\end{tabular}

Eventually we look at a setting embedding distortive taxes. This time we tax proportionally both labor and capital. The results are displayed in table 9 and correspond to the setting $I M_{6}$. The introduction of distortive taxation does not change fundamentally our findings. Nevertheless it suggests that when taxation distorts capital accumulation, public debt is a little less helpful for precautionary saving motive as the increase in the interest rate is accompanied by a rise of the capital tax rate.

\footnotetext{
${ }^{5}$ More detail on the relaxing of the borrowing constraint can be found in Aiyagari and McGrattan (1998).
} 
Table 9: Impact of public debt under distortive taxation

\begin{tabular}{|c|c|c|c|c|}
\hline & \multicolumn{3}{|c|}{ (\%) Consumption cost of population } & \multirow{2}{*}{$\begin{array}{c}\text { (\%) Constrained } \\
\text { agents }\end{array}$} \\
\hline & All & Least fortunate $5 \%$ & Most fortunate $5 \%$ & \\
\hline$I M_{3}$ & 0.0549 & -0.4059 & 0.4238 & 1.5482 \\
\hline$I M_{6}$ & 0.0329 & -0.3532 & 0.4147 & 1.6225 \\
\hline
\end{tabular}

\section{Conclusion}

This paper reconsidered the optimal level of public debt in an environment of aggregate fluctuations. Our main finding is that a positive public debt level of $65 \%$ of output is optimal. This level is higher than in an economy without aggregate fluctuations. However for the poorest agents in the economy, higher levels of debt are not optimal. Poor agent rely mainly on labor income and are dependent on higher wages and lower taxes. Public debt decreases wages and increases tax level thus poor agents prefer lower levels of public debt. To support our main finding we quantitatively looked at the importance of market completeness, credit constraints, price behavior and distortive tax policies. We find that price fluctuations alone, namely interest rate increases, explain the optimality of a positive level of the debt to GDP ratio when markets are incomplete.

All our findings derive from long term steady state results. The next step to better understand public debt is to give a closer look at the short term. 


\section{Appendix}

\section{A Computational strategy}

We solve the model using the methodology developed by Krusell and Smith (1998). They show that agents need only a restrictive set of statistics to determine prices. This set includes the mean of the wealth distribution and the aggregate productivity shock. A linear prediction rule based only on the average level of capital provides an accurate prediction. This result comes from the near linearity of the decision rule $a^{\prime}(a, s, \beta ; z, \Gamma)$. As the aggregate capital stock is mainly held by rich people who have approximately the same propensity to save, next period's aggregate capital is accurately predicted by current period's aggregate capital. In our model, we assume the following law of motion:

$$
\log \left(\bar{K}^{\prime}\right)=a_{0}+a_{1} z+a_{2} \log (\bar{K})
$$

where $\bar{K}^{\prime}$ and $\bar{K}$ denote respectively the average stock of capital of the next period and of the current period. Thus the strategy is the following:

(Step 1): Given a set of parameter values $\left(a_{0}, a_{1}, a_{2}\right)$ for the law of motion, we solve the individual problem. Unlike Krussel and Smith (1998) whom solve the Bellman equation by value function iteration on a discrete grid, we use the Parameterized Expectations Approach (PEA). This method consists in the approximation of the conditional expectation in the Euler equation,

$$
U^{\prime}(c)=E\left[\beta^{\prime} U^{\prime}\left(c^{\prime}\right)\left(1+r^{\prime}\left(z^{\prime}, \Gamma^{\prime}\right)(1-\tau)\right) / s, \beta ; z, \Gamma\right],
$$

by a flexible polynomial $h(a, s, \beta, z, \bar{K}, \psi)$ that depend on the state variables and some coefficients $\psi$ that we must estimate. To identify those coefficients, we use projection methods on the state space grid. Projection methods turn out to be efficient when using orthogonal polynomials such as the Chebyshev polynomial family. We only approximate the conditional expectation when the borrowing constraint is not binding. Otherwise consumption can be deduced from the budget constraint.

(Step 2): Given the parameter values for individual decision rules, we solve the aggregate problem i.e. the coefficients of the law of motion. 
(Step 3): If the parameters $\left(a_{0}, a_{1}, a_{2}\right)$ found are close to the parameter values used to solve (Step 1), the algorithm has converged. Otherwise (Step 1), (Step 2) and (Step 3) are repeated until convergence. 


\section{References}

[1] Aiyagari, R., 1994, Uninsured Idiosyncratic Risk and Aggregate Saving, The Quarterly Journal of Economics, 109, 659-84.

[2] Aiyagari, R., McGrattan, R.E., 1998, The Optimum Quantity of Debt, Journal of Monetary Economics, 42, 447-469.

[3] Algan, Y., Allais, O., 2004, Incomplete Unemployment Insurance under Aggregate Fluctuations, Economics Bulletin, 5(12), 1-7.

[4] Auerbach, A., Kotlikoff, L., 1987, Evaluating Fiscal Policy with a Dynamic Simulation Model, Papers and proceedings of the ninety-ninth annual meeting of the American Economic Association, 49-55.

[5] Barro, R., 1989, The Ricardian Approach to Budget Deficits, Journal of Economic Perspectives, 37-59.

[6] Ball, L., Mankiw, G., 1995, What Do Budget Deficits Do?, in Budget Deficits and Debt: Issues and Options. Symposium Proceedings, Federal Reseve Bank of Kansas City, 95-119.

[7] Carroll, C., 2000, Requiem for the Representative Consumer? Aggregate Implications of Microeconomic Consumption Behavior, American Economic Review Papers and Proceedings, 90, $110-115$.

[8] Floden, M., 2001, The Effectiveness of Government Debt and Transfers as Insurance, Journal of Monetary Economics, 48, 81-108.

[9] Hansen, G., Imrohoroglu, A., 1992, The Role of Unemployment Insurance in an Economy with Liquidity Constraints and Moral Hazard, Journal of Political Economy, 100, 118-142.

[10] Hayashi, F., 1985, The Effect of Liquididty Constraints on Consumption : a Cross-sectional Analysis, Quarterly Journal of Economics, 100, 183-206.

[11] Heathcote, J., 2005, Fiscal Policy with Heterogeneous Agents and Incomplete Markets, Review of Economic Studies, 72, 161-188. 
[12] Imrohoroğlu, A., 1989, Cost of business Cycles with Indivisibilities and Liquidity Constraints, Journal of Political Economy, 97, 1364-1383.

[13] Japelli, T., 1990, Who is credit constrained in the U.S. Economy ? Quartely Journal of Economics, 105, 219-234

[14] Krusell, P., Smith, A., 1998, Income and Wealth Heterogeneity in the Macroeconomy, Journal of Political Economy, 106, 867-896.

[15] Krusell, P., Smith, A., 1999, On the Welfare Effects of Eliminating Business Cycles, Review of Economic Dynamics, 2,245-272.

[16] Krusell, P., Smith, A., 2002, Revisiting the Welfare Effects of Eliminating Business Cycles, Working Paper.

[17] Storesletten, K., Telmer, C., Yaron, A., 2001, The welfare cost of business cycles revisited : finite lives and cyclical variation in idiosyncratic risk, European Economic Review, 45, 13111339

[18] Woodford, M., 1990, Public Debt as Private Liquidity, American Economic Review, 80, 382388.

[19] Zeldes,.S, 1989, Consumption and Liquidity Constraints : an Empirical Investigation, Journal of Political Economy, 97, 305-346 